\title{
A Critical Review on Some Key Terms Taken from The Virtual Community by Howard Rheingold
}

\author{
Xiaowei Huang ${ }^{1}$ \\ ${ }^{1}$ School of Art \& Design, Guangzhou College of Commerce, Guangzhou, China \\ Correspondence: Xiaowei Huang, School of Art \& Design, Guangzhou College of Commerce, Guangzhou, \\ Guangdong Province, 511363, China. Tel: 86-188-0253-8544. E-mail: janey710@yahoo.com
}

Received: June 20, 2019

doi:10.5539/ass.v15n9p46
Accepted: July 23, 2019 Online Published: August 30, 2019

URL: https://doi.org/10.5539/ass.v15n9p46

\begin{abstract}
This paper aims to review and re-examine some of the key terms taken from Howard Rheingold's book The Virtual Community, which was published in 1998. Even though it has been 2 decades since this book was published, Rheingold's ideas are affective and applicable to the current research on virtual community. As the first man who invents the term 'virtual community', Rheingold provides a number of significant contribution and offers more room for the further studies on virtual community, as well as virtual world. Rheingold's foresight on the understanding of virtual community has great impact on the current studies of the virtual world.
\end{abstract}

Keywords: virtual community, virtual world, WELL, CMC, panopticon

\section{Introduction}

Even though there are a great deal of changes and improvement on the topics that relate to the field 'virtual' comparing with Rheingold's time, it is also noticeable that Rheingold's book does not provide intensive explanation on certain topics and theoretical terms, what the book calls us, as communication scholars, or educators for action is to discover areas that have not been researched or, in addition, to compare similarities and differences function and impact that virtual community works on the contemporary participants with those in twenty years ago. Virtual community is a wide term under the umbrella of Communication studies. It would be a goal that seems unattainable if one would like to fully analyze it. What is suggested here is to fill the gaps of emptiness and seek for new areas or destinations for further research.

There are total ten chapters in the book. Rheingold first introduces the term 'WELL' on the first chapter. Chapter two analyzes 'Daily Life in Cyberspace: How the Computerized Counterculture Built a New Kind of Place'. In chapter three, Rheingold takes us back to the Accidental History of the Net. Following in chapter four he begins to discuss 'Grassroots Groupminds'. Chapter five is an interesting chapter which is emphasized on 'Multi-user Dungeons and Alternative Identities'. In chapter six, the topic of 'Real-time Tribes' is discussed. Rheingold provides the relationship between the Net and specific region by using Japan as an example. This content is in chapter seven: Japan and the Net. In chapter eight, Rheingold turns the readers' attention to the introduction of 'Telematique and Messageries Rose: A tale of Two Virtual Communities'. Rheingold also analyzes the 'Electronic Frontiers and Online Activists' in chapter nine. Last but not least, as the last chapter of the book, Rheingold's interpretation on 'Disinformocracy' is introduced in chapter ten.

Everyone has only 24 hours a day, and during that period our time is always taken up with and 'spent' moving from one space to another. Time and space are the most crucial elements that limit the capacity of human life. The invention of the airplane, for instance, shortens the time of transportation and reduces the distance between places. However, there is still a little to do. We can take a day trip from Hong Kong to Singapore, but it is impossible to present a research paper at an international conference that is held in San Francisco in the same day. We can attend church Sunday service in the morning. Have lunch with friends in a nice open-air restaurant; take a nap on a super comfortable king-size bed and play basketball straight afterward; then enjoy a romantic candlelight dinner with boy/girl friend. Unfortunately, you might think of your best friend who is getting married in Japan while listening to the speech of the pastor, you wish to see her happy face and congratulate her. We cannot be in two places at once. The real world that we live in everyday has so many restrictions that limit what we wish to be. However for Howard Rheingold, virtuality provides an alternative. 


\subsection{The WELL}

As for Rheingold, the invention of virtual community, virtual space, as well as virtual world, and the rise of virtual communities, constitute the critical development for humanity. It influences the way how people work, how people behave both in public and private. Further more, it changes the lifestyle and almost every aspect of human life. He stresses that 'I have good friends now all over the world who I have never would have met without the mediation of the Net' (1998). It seems to him that the intention of communication technology, such as WELL (Whole Earth 'Lectronic Link' (1998), has changed the way how people make friends from the traditional way, which requested the meeting in physical world at least. Traditionally, people could make friend through exchanging written letters, it was one way that people could build friendship without a physical meeting. However, geographic distance could make letters always been delivered after the problem was solved. It is no deny that exchanging letters could be an alternative way for making friends, but it seems quite hard for a further development of the friendship. For example, if someone was at a moment of difficult time about his job, he decided to write his feeling down on a letter and send it to his friend for advice. After he received the feedback from his friend that he was asking for advice, he may either have found a new job, or he might not feel the same as how he felt the moment when he wrote the letter. Time consuming is one of the most critical restrictions for almost every type of relationship. With the invention of WELL, time consuming is no longer a problem. Within only a minute, an email could be sent to the receiver.

\subsection{The Meaning of 'Real'}

Rheingold's appreciation on meeting good friends via the Net sounds interesting. However, it may be questionable that whether or not we should consider the friendship we build through the Net a real friendship? This could lead to some further questions about the experience or relationship that we gain from the Net is real too. For example, does the virtual world an extension of the offline world? What make(s) a virtual world popular? In what ways? Rheingold, who invented the term 'virtual community', addresses these questions and other issues in this book. The term 'real' exists like a twin brother of the 'virtual'. In Rheingold's opinion, 'the phrase 'in real life' pops up so often in virtual communities that regulars abbreviate to IRL" (1998). However, Rheingold's description about the 'real' is too general. It seems a common understanding that the virtual is an opposite term of the real. In this sense, we may question that whether or not activities taken place in the virtual world, for example, sending and receiving email, and the way how the Internet users access to the information on e-bulletin are considered as real actions. In this case, it is important to understand how 'real' is defined in the relationship with the virtual community. Instead of directly define the term 'real', Chalmers raises a question of 'is virtual reality real?' Before he express his understanding on this question. His answer is that:

The common view is that virtual reality is a sort of fictional or illusory reality, and that what goes in in virtual reality is not truly real. I will define the opposite view: virtual reality is a sort of genuine reality, and what goes on in virtual reality is truly real (Chalmers, n.d., p. 1).

Charlmers' idea about how the meaning of 'real' is defined in virtual reality shares some similarities with Rheingold's. They both do not deny the realistic of the virtual reality and experiences. Rheingold points out that 'the WELL (a computer conferencing system that enables people around the world to carry on public conversations and exchange private electronic mail) felt like an authentic community to me from the start because it was grounded in my everyday physical world' (1998). If actions of sending emails, browsing websites, accessing e-bulletin are considered as 'virtual actions' only, which may be assumed that is unreal. What are 'real or physical actions' stood for? This question seems controversial. Virtual activities would not happen without actions taken in the physical world. For example, sending emails requests the action of typing on keyboard. Before browsing a website we also need to key in the website on the Internet server.

\subsection{Virtual Community}

Virtual community does not only about the activities of sending and receiving emails. In the contemporary world, its activities has been expanded to online games and the participation of the virtual world, which are more about role playing experiment and simulation. It seems to Rheingold that it is not necessary whether or not the friends he met through the Net would lead to a physical meeting. However, those friends do help him to gain new knowledge, such as a specific culture of a place, or a country. He shares his experience that 'I've found ready-made communities that I met online before I traveled; out mutual enthusiasm for virtual communities as a bridge, time and again, to people whose language and customs differ significantly from those I know well in California' (1998). Exchanging ideas and sharing custom could be the major parts that most virtual community members do for online communication, as there are a large number of topics to talk about even within two people who have never met physically. This is also one of the key reasons why virtual communities are more and 
more popular twenty years later after Rheingold's sharing of his experience.

According to Rheingold, a virtual community can have a number of forms. It can be a computer conference system, the WELL for instance. This allows people to hold their conversations and send emails to each other. It can be a role-play game where people take an alternative identity. It can be a community that crosses different countries and cultures via email to connect with people all over the world. Rheingold explains that even though methods that people use for communicating on the screen are limited. For example, people can only use typed words to exchange ideas and opinions, however, it does not affect too much about people's enthusiasm of participating online. This could be answered why more and more people enjoy making friends via virtual community. Seeking for emotional support is one of the key reasons why people take part in virtual world.

Although there is a missing part of friendship that is built through the Net, which is the part of physicality, one critical aspect that we must never forget is: people have emotion, feeling, and love. Without a physical meeting of each other does not mean that the person on the other side of the screen is different from who they are in the physical world. Rheingold expresses his agreement on this: 'I'm not alone in this emotional attachment to an apparently bloodless technologies ritual' (1998). The only limitation is that in virtual community you are not able to show your facial expression, which is reflected about sadness or happiness. However, a person can use words as an alternative to express his/her feeling. It should not be questionable about activities that are taken through the Net is unrealistic or even unbelievable. It is a common sense that some people may worry about the friend that makes online is not trustable. We may ask that how can you $100 \%$ ensure that friend you make in the physical world is reliable? Some people may feel more comfortable talking to friends via virtual community than in the physical world. Virtual community allows them to be more open and offers more freedom for them to share ideas and personal insights. To some extent that they do not have to worry too much about their opinion they share that may lead to serious consequence.

\subsection{Communication Technology}

It seems to Rheingold that virtual community provides certain degree of social experiments for its participants. It changes the way how people gain social experiments through the physical world. As he puts it:

We now know something about the way previous generation of communication technologies changed the way people live. We need to understand why and how so many social experiments are coevolving today with the prototypes of the newest communications technologies (1998).

It is no deny that the way how people live is very different from what they were before the invention of communication technology. These changes are not only based on those who join virtual community, but also the invention of mobile phone, for instant, which has great impact on the way how people communication with each other via digital device. Traditional people use mobile phone to make phone calls, which requests voice communication. The invention of iPhone has overturned the way how people use the mobile phone, along with many applications (Apps) are available for downloading on the mobile phone, people hardly make phone calls, they are more keen to send text messages through an App, for example, WhatsApp. Making a phone call is no longer the only way that makes communication feasible between users. The availabilities of chatting Apps offer more channels to the mobile phone users in order to fulfill the purpose of communication. The way how people use mobile phone in the contemporary world is similar with how people use virtual community for. Virtual community does not function merely as to send and receive emails, it offers the users with various purposes.

\subsection{The $C M C$}

Rheingold provides several key concept's definitions in the par of 'Introduction'. Namely: The Net; Virtual communities; and Cyberspace. He defines The Net is 'an informal term for the loosely interconnected computer networks that use CMC technology to link people around the world' (1998). Virtual communities 'are social aggregations that emerge from the Net when enough people carry on those public discussions long enough, with sufficient human feeling, to form webs of personal relationship space' (1998). In the case of Cyberspace, he explains that it is 'originally a term from William Gibson' science-fiction novel Neuromancer, is the same some people use for the conceptual space where words, human relationships, data, wealth, and power are manifested by people using CMC technology' (1998). We can see the term 'CMC' appears quite often within these definitions, however, Rheingold does not provide the meaning of what ' $\mathrm{CMC}$ ' stands for. It makes it difficult to connect this term with the later content where he discusses ' $\mathrm{CMC}$ ' and its impact on people's lives. As Rheingold writes it:

CMC has the potential to change our lives on three different, but strongly interinfluential, levels. ... CMC appeals to us as mortal organisms with certain intellectual, physical, and emotional needs. ... the second 
level of possible CMC-triggered change is the level of person-to-person interaction where relationships, and communities happen. ... The third level of possible change in our lives, the political, derives from the middle, social level, for politics is always a combination of communications and physical power, and the role of communications media among the citizenry is particularly important in the politics of democratic societies (1998).

The quote above taken from Rheingold's book under the part of Introduction. The first level about how CMC affects people's lives, Rheingold expresses that 'the way we use the medium and the ways it uses us' are 'shaped by other communications technologies' (1998). This claim is very unclear. It is understandable about how our perceptions, thoughts, and personalities are affected by the ways we use communication technologies. For example, people with different personalities may have different way to send messages on mobile phone through an App. For older generation, people are more keen to use voice messaging than text messaging. However, this phenomenon does not only happen to the senior people, but also young generation. Many young people would prefer using text rather than voice messaging, as it allows them to re-think and re-type the message before it is sent. This has not direct relation to one's personality, for example, a quiet or shy person may not like to use voice messaging. What makes Rheingold's claim unclear is the statement of 'the ways it uses us' (1998). Firstly, this sentence has grammatical error. Secondly, it is very confused about what 'it' is referred to here? Finally, if the term 'it' is referred to 'communication technologies', how can we, as human are used by communication technologies? This is problematic. We believe that Rheingold provides some useful ideas in terms of CMC, but it is important for us, as the book readers to be provided a full name of certain professional terms instead of simply an abbreviation. Moreover, a clear structure of sentences plays a critical role to help readers better understand what the author means exactly. By doing so, we can avoid making assumption or create misunderstanding.

Moreover, the communication scholar McLuhan's name is first introduced by Rheingold in the content of CMC's impact on peoples' lives. Instead of neitherputting McLuhan's name (which should include the first name) directly, nor providing a particular quote of McLuhan that Rheingold would like to refer to, Rheingold simply use the term 'pre-McLuhanized', which is confusing and unclear about what he is trying to talk about. McLuhan's well-known writing 'The medium is the message' could be one of the possibilities about what Rheingold refers to. However, it is only a piece of consumption without confirmation. It makes it difficult for the readers who may not have read McLuhan's work previously. Even if one may have done so, it is important for the author to explain it and shows how a particular theory is applied to, and in what ways.

Rheingold provides two examples to analyze the first impact of CMC. The first one is how a medium is used and the way how people's lives are affected by the medium. The second example is MTV. Rheingold uses it as to draw readers' attention to the way how young generation no longer pay too much attention on television and telephone. Instead, young people are more attracted by the online interactions. In Rheingold's point of view that the age of media saturation is changed by human personalities, which is what he points out at the first claim about 'personalities [are] already shaped by other communication technologies' (1998). From this critical review's perspective that a person's personalities have less or no relation to the usage of communication technologies. It is merely about personal preference on how a person interacts with a particular device.

The second level of CMC's impact is on interpersonal relationship. It seems to Rheingold that it could be a challenge to build some kind of community with those who gain different value through the community. One of the major reasons is that people create groups or join a community with those who share similar value, or the value is gained through by banding together. This could lead to the isolation, or limit the chances of interaction. Marc Smith, a graduate student from UCLA who conducts his fieldwork in the WELL and the Net, calls it 'collective goods' (Rheingold, 1998).

\section{Discussion}

To begin with a small but important point, Rheingold uses quite a number of abbreviations, such as WELL, that play a key role in his work. However, these abbreviations should have been given in full the first time they appear. Consequently it is hard for a reader who has not that much familiarity with the field of computer science to follow the ideas. For example, Rheingold invites the term ARPANET as the first time that it appears in his book. He introduces that 'ARPANET is the first computer network, it was created in the 1970s' (1998), but what ARPANET stand for? As another key word in this article, there is no annotation to explain this word. Secondly, there are three terms that need elaborate explanations: the net; virtual communities; and cyberspace. These words are more or less similar in terms of their definitions, and it is difficult to make a clear distinction between each of them. The author only takes a paragraph to define each term.

Further, the structure of this work is difficult to understand and follow. For example, Rheingold shares his 
experience in the virtual world, and it seems to the reader that he has a wonderful time being there, with friends that he knows and with those who meet only through the virtual community. However after discussing these experiences, he suddenly changes to another topic that has not so much connection with the previous one, and it is hard for the reader to follow. Finally, there is the issue of Rheingold's attempt to remind people that they should keep their eyes open in virtual communities in case they fall into a trap. However, when he mentions that 'the future will be shaped for us by large commercial and political power holders' (Rheingold, 1998), there is no explanation linking what has gone before to this development. It would have helped if he had provided some examples to explain why he has this concern, and how they can be avoided.

Rheingold's introduction is too short to cover such a big topic and the many theoretical terms and issues that are used to research and give an account or explanation of it. Rheingold limits himself to two major themes in his work. The first one is about virtual communities and technology, and the second one is about the concerns and expectations of the author. However Rheingold does not organize this work very clearly, and the examples that he provides in the text are interesting but need further explanation and linkage to the points that he is explaining.

Rheingold draws readers' attention to his major concern about new technology, specifically in terms of the mixing of technology (Rheingold, 1998). He explains that personal computers are affordable for most ordinary citizens. For Rheingold, the technology provides its users both positive and negative experiences. On the one hand, freedom is a big issue as people enjoy much more freedom online than offline world. On the other hand, people may experience harm or vocal violence online. He agrees that virtual community offers certain degree of freedom to its users in many ways that they are denied in the real world, however, people should be more critical on how difference opinion is shared online in order to avoid being manipulated by commercial and political power holders (Rheingold, 1998). He turns his focus to the introduction of the ARPANET, which was the first computer network. He firstly provides brief background information about how ARPANET was invented. Secondly, he points out that the development of ARPANET was accompanied by other inventions, such as electronic mail, which was not the plan of the programmers initially (Rheingold, 1998). Finally, Rheingold switches his focus to the introduction of the BBS and its functions. As for some virtual community users that there is a clear boundary between online and offline world. In other words, these users may claim that there is no overlapped between the two worlds. As for Rheingold, his offline life is somehow affected by the experience that he gains online.

It is quite clear that Rheingold's intention is to remind people that they should not be passive in virtual communities. It is very important to have a good understanding of things that go on in the everyday life of virtual world. It is interesting to read about virtual world experiences and how people interact with each other. Moreover, the author uses his own experience gained from the activities that he attended. Rheingold mentions about real-life WELL marriages, WELL births, and even a WELL funeral that he attended.

\section{Panopticon}

Rheingold uses Benrham's term 'panopticon' after briefly introduces the terms WELL and ARPANET. Panopticon is used as a metaphor in order to express his concern about how privacy and information are brought out from citizens' home. Initially it is that the information is brought into citizens' home. However, the development of technology makes it an interactive ways, which allows the information to be spread from home via the cables. Why Rheingold uses panopticon as a metaphor to show his concern? What is the meaning of panopticon?

\section{According to Schirato, Danaher, and Webb:}

Panopticon was a tower placed in a central position within the prison. From this tower, the guards would be able to observe every cell and the prisoners insides it; however, it was designed in such a way that the prisoners would never know whether they were being observed or not. Prisoners would assume that they could be observed at any moment and would adjust their behaviour accordingly (2012, p. xxiv).

Rheingold does not provide a detail explanation of the term panopticon. Within a single paragraph where panopticon is first introduced to the readers, Scholar Jeremy Bentham, who invents the term Panopticon, and Michel Foucault's work Discipline and Punish are briefly brought into the discussion. Rheingold's decision on using both scholars' works is useful for the discussion about privacy and information. However, to provide some additional information about these works is necessary. Firstly, Panopticon could be a new term for those who are not specifically working under the field of Communication. It makes it difficult for general readers to understand what it is meant. In this case, it would be helpful and important to provide some background information about the term, for example, what makes Panopticon relevant to the way how privacy and information are brought into and out from citizens' home. Secondly, Michel Foucault's works are widely influential on many fields and 
disciplines, such as sociology, psychology, as well as communication. Schirato, Danaher, and Webb write that '... his work on power, discourse, subjectivity, disciplinarity, surveillance and normativity can contribute to our understanding of the contemporary world and its practices' $(2012$, p. 1).

It is clear that Foucault's theories, in particularly, on surveillance is supportive in relation to the content of privacy and information. However, it seems that Jeremy Bentham's concept of panopticon is not so much applicable to the same topic. The main idea of panopticon is that prisons assume that they are being observed anytime by living in the 360 degree of panopticon. They adjust their behaviors accordingly in order to avoid making any inappropriate mistake. Rheingold connects Foucault's claim that 'the machinery of the worldwide communications network constitutes a kind of camouflaged panopticon; citizens of the world brought into their homes, along with each other, the prying ears of the state' (1998). Rheingold paraphrases Foucault's claim without putting any reference, such as the page number of the book and year of publishing. This paraphrasing seems incomplete, moreover, the contextualize content is needed and helpful if Rheingold could write more about it, by doing so, it can help the readers to understand what exactly Foucault's claim is about, for example, under what circumstance or historical background that Foucault's idea is from. Foucault's theory on surveillance has greater connection with the concept of panopticon. In the book Understanding Foucault written by Schirato, Danaher, and Webb, they write that

The most significant metaphor for explaining the relation between apparatuses and surveillance, Foucault contends, is the panopticon. ... in previous penal regimes, prisoners had been removed from sight either in dungeons or by transportation, but the panopticon worked on an entirely different principle - that the best way of managing prisoners was to make them the potential targets of the authority's gaze at every moment of the day (2012, pp. 87-88).

Returning to the connection with privacy and information and the way how they are spread, who are the prisoners? And who are the guards? Without clear answers of these question, it is impossible to understand the idea of 'prisons adjust their behavior accordingly', because there is no confirmation about who are being observed. It is the author's job to provide explanation and make every claim clear instead of leaving the questions to the readers. Even though Rheingold's critic is that 'the cables that bring information into our homes today are technically capable of bringing information out of our homes, instantly transmitted to interested others' (1998). It is still not so relevant to the meaning of that panopticon targets to.

It seems to Rheingold that on the one hand, he shows his appreciation on the invention of virtual community at the beginning of the introduction, on the other hand, he suddenly changes his attitude on it when he begins to bring in Bentham and Foucault's works. He uses the example of 'we should not forget that intellectuals and journalists of the 1950s hailed the advent of the greatest educational medium in history - television' (1998) in order to support his claim about the humanitarian potential of virtual community. This example is only in a single sentence that has no specific name of who the intellectuals and journalists were. Moreover, there is no further explanation about this example after the sentence is complete. The writing style that Rheingold applies to his work is very brief and abstract. For example, the works of Bentham and Foucault should be at least discussed in two separate paragraphs. This includes provide definitions of the key concepts, background information of the theoretical terms, examples that help to link the author's concern or claims that is related to those concept.

\section{Conclusion}

Rheingold does not clearly present his position on virtual worlds. In the conclusion, Rheingold has not made an argument as to whether the invention of the virtual community is a good or a bad thing. It is obvious that Rheingold has his concerns about the increasing number of virtual communities and their participants. However, his discussion of these concerns is rather superficial. This is a problem given that the question of whether or not the human life has been affected by the rapid development of information technology and virtuality has been widely discussed in academic literature. When he does take a position, it is sometimes hard to know what he means, or to make sense of the significance of his statements. One example of this is his final sentence: he confesses that 'I've been colonized; my sense of family at the most fundamental level has been virtualized' (Rheingold, 1998).

Rheingold's work lacks evidence and explanations. For example, when Rheingold talks about the case of people being addicted to virtual communities, such as Minitel in France and Multi-User Dungeons, he needs to provide a further explanation about the reasons why these communities were banned at universities in the U.S. Moreover, the author uses too many unexplained professional terms in the subject area of computer science; again, there are very few explanations or examples. There also should have been a brief history or a timeline provided so that the reader could easily understand which developments came first, for instance. That would have made his account 
easier to follow.

To sum up, this is an interesting piece of work but it does not function well as a piece of serious research. However it does provide a better understanding of the virtual community. It is also interesting to read about the virtual experiences of the author. These accounts of the author's virtual experiences provide the basis for further discussion on the subject area, and they will be useful to my dissertation topic.

\section{References}

Chalmers, D. (n. d.). The virtual and the real. Retrieved from http://consc.net/papers/virtual.pdf

Rheingolad, H. (1998). The Virtual Community. Retrieved from http://www.rheingold.com/vc/book/intro.html

Schirato, T., Danaher, G., \& Webb, J. (2012). Understanding Foucault. Sydney: Allen \& Unwin.

\section{Copyrights}

Copyright for this article is retained by the author(s), with first publication rights granted to the journal.

This is an open-access article distributed under the terms and conditions of the Creative Commons Attribution license (http://creativecommons.org/licenses/by/4.0/). 